\title{
Risk factors for complications after robotic adrenalectomy: a review
}

\author{
Davide Inversini ${ }^{1}$, Livia Manfredini ${ }^{1}$, Federica Galli ${ }^{2}$, Dai Zhang ${ }^{3}$, Gianlorenzo Dionigi ${ }^{4}$, Stefano Rausei ${ }^{2}$ \\ ${ }^{1}$ Endocrine and Metabolic Surgery, University of Insubria, Varese, Italy; ${ }^{2}$ Department of Surgery, ASST Valle Olona, Gallarate, Italy; ${ }^{3}$ Division of \\ Thyroid Surgery, Jilin Provincial Key Laboratory of Surgical Translational Medicine, China-Japan Union Hospital of Jilin University, Changchun \\ 130600, China; ${ }^{4}$ Division for Endocrine and Minimally Invasive Surgery, Department of Human Pathology in Adulthood and Childhood "G. \\ Barresi”, University Hospital G. Martino, University of Messina, Messina, Italy \\ Contributions: (I) Conception and design: D Inversini, G Dionigi, S Rausei; (II) Administrative support: G Dionigi, S Rausei; (III) Provision of \\ study materials or patients: L Manfredini, F Galli; (IV) Collection and assembly of data: F Galli, D Zhang; (V) Data analysis and interpretation: D \\ Inversini, D Zhang, G Dionigi, S Rausei; (VI) Manuscript writing: All authors; (VII) Final approval of manuscript: All authors. \\ Correspondence to: Stefano Rausei, MD, PhD. Department of Surgery, ASST Valle Olona, Via Pastori 4, 21013 Gallarate (Varese), Italy. \\ Email: stefano.rausei@gmail.com.
}

\begin{abstract}
The application of adrenal surgery has been spreading steadily in recent years. With the increased use of robotics in surgery, robotic adrenalectomy (RA), especially for the posterior retroperitoneoscopic approach, has been taken on by many high-volume institutions as a good option over the standard laparoscopic approach (LA). This paper reviews the recent literature from May 2010 up to November 2019 with the aim of analyzing RA complications in order to identify risk factors for complications after RA. We analyzed 7 principal risk factors for complication: body mass index (BMI), age, tumor size, tumor side, pathology, previous surgery, and surgeon experience. In the review, some studies identified tumor size, malignancy type, completion of learning curve and, and less clearly, previous ipsilateral upper mesocolic or retroperitoneal surgery, as risk factors for postoperative complications and failure of robotic surgery. Whether RA is meaningfully superior to the standard minimally invasive approach is still a subject of discussion. RA appears safer by virtue of its reduction in hospital stay, lower blood loss, and equivalent complication rates, and surgeons should prefer adrenalectomy over the LA. Despite these advantages, the operative time and the overall cost of the robotic procedure are higher than the LA. Further high-quality trials, especially those analyzing the specific risk factors for complications in robotic surgery, should be conducted in order to optimize the stratification of patients eligible for robotic surgery.
\end{abstract}

Keywords: Robotic adrenalectomy (RA); risk factors; complications

Submitted Nov 27, 2019. Accepted for publication Mar 25, 2020.

doi: 10.21037 /gs.2020.04.10

View this article at: http://dx.doi.org/10.21037/gs.2020.04.10

\section{Introduction}

Adrenal surgery is becoming more frequent worldwide. The improvements of modern imaging methods, along with an increased detection of adrenal lesions and new surgical techniques linked to the reduction of morbidity and mortality (1), have prompted an increase in indications for resective surgery (2).

With the increased use of robotics in surgery, robotic adrenalectomy (RA), especially in the posterior retroperitoneoscopic approach, has been taken on by many high-volume institutions as a good option over the standard laparoscopic approach (LA). In adrenal gland surgery, the advantages of minimally invasive surgery, compared to open adrenalectomy, are already well known in the literature (3). RA allows precise movements in limited working spaces, higher video resolution, and better sensation to the surgeon, while its functional design facilitates the surgeon's ease of use intraoperatively $(3,4)$. 
These benefits may be helpful, especially during dissections in critical and tight fields. RA has proven particularly useful in the posterior retroperitoneoscopic approach where the surgical field is restricted. It has shown its value when managing anatomic variants and when using the corticalsparing technique as it can help achieve reliable resection while decreasing post-operative steroid dependence $(5,6)$. Despite these strengths, RA has not yet demonstrated substantial superiority in terms of reducing blood loss, or improving conversion and complication rates compared to the LA; meanwhile it still requires considerably longer operative times (7). We must also consider the sizeable learning curve needed for the application of robotic equipment, including advanced laparoscopic surgeons $(5,7)$. Notwithstanding the considerably shorter recovery period for patients undergoing robotic surgery, the total cost of the robotic procedure is also lower than that of the LA (7-9). This review aimed to investigate the incidence of RA complications and to identify the risk factors for the incidence of intra and postoperative complications.

\section{Methods}

We evaluated the recent literature (from May 2010 up to November 2019) on PubMed Central. Our research was based on the following terms: "robotic adrenalectomy", "robotic adrenal surgery", "robotic", "complication", "risk factor", "risk factor for complications", and "conversion". All abstracts were read separately by 2 different reviewers. The scientific relevance of the papers was assessed by considering the number of patients, the accuracy of the statistical method, and the originality of the article. Each paper selected was read by at least 2 reviewers, and the pieces that were considered scientifically relevant have been included in the reference section.

\section{Results}

\section{Complications}

The incidence of postoperative complications in RA was found to be around 9.2-12.5\% (10,11); medical complications, which includes urinary infection, pulmonary infection, and postoperative hypotension, occurred in $2.3 \%$ of patients, while surgical complications occurred in $6.9 \%$ of patients (10).

The incidence of conversion was lower than $2-13 \%$ for laparoscopic surgery and robotic surgery (11-13). The exigency for conversion was not linked with patient age, body mass index (BMI), tumor size, laterality, or pathology, although there was a trend of Cushing's patients undergoing conversions (11).

Complications associated with robotic adrenal surgery were hemorrhage and bleeding (incidence of 3-4\%) $(9,14)$ with need for transfusion, hematoma (incidence of $0.7 \%$ ) (10), wound and local infection, abscess (incidence of $1.7 \%$ ) (10), urinary tract infection, adjacent organ injuries with laceration of adjacent organs, ileus (incidence of $3 \%$ ), and complications related to the laparoscopic procedure and atelectasis (incidence of $3 \%)(2,15)$. One of the most frequent complications was incisional hernia, which occurred in $2.6 \%$ of patients in RA (10).

Minor complications were fever and pleural effusion (16). The complication rate, postoperative morbidity, and mortality between the robotic and laparoscopic groups were comparable to conventional laparoscopic adrenalectomy $(4,17)$.

The occurrence of complications led to an increase in the length of hospital stay. The length of stay in patients who developed any complication was 10 days, whereas it was 3 days in those who did not (16).

A recent systematic review carried out by Heger et al. included 26 trials, pooling 1,710 cases; no significant disparity between open and minimally invasive techniques for postoperative complication rate were reported. Laparoscopic and robotic approaches seem to be similar. Surgery duration was considerably lower for open adrenalectomy, which was found to be a faster technique than the robotic approach. However, RA reduced bleeding compared with open and laparoscopic surgery, and robotic access was significantly associated with a significant reduction of length of hospital stay, although this divergence was not congruent in the randomized controlled trials (RCTs) (18).

Data regarding complications were also supported by a recent meta-analysis carried out by Economopoulos et al., in which 27 studies were included, pooling 1,162 patients admitted to adrenal surgery (747 underwent RA and 415 underwent conventional LA). No substantial difference was found between the RA and LA groups for intraoperative complications, postoperative complications, mortality, and conversion to laparotomy and blood loss. Patients who underwent the robotic approach had a notably shorter hospitalization and a significantly longer operating time (7). These data are confirmed by Agrusa et al.'s systematic review comparing RA and LA, which included 13 papers, 
pooling 798 patients, 379 of whom underwent RA and 419 of whom underwent the LA. The paper did not find any substantial difference in age, although the RA group showed a lower bleeding rate and a shorter hospital stay (19).

Meanwhile, Samreen et al., also found no discrepancy in complication and conversion incidence between robotic surgery and the LA. In their retrospective trial, comprising a total of 1,006 patients (66.4\% in the LA group and 33.6\% in the RA group) the mean hospital stay was shorter in the robotic group, but the total expenses were higher (12). Therefore there were no differences in the post-operative care between the 2 groups, but the length of hospitalization in RA group was shorter while RA involved higher costs than the laparoscopic or open approach (12).

\section{Risk factors for complications}

In this non-systematic review we analyzed RA complications in order to identify risk factors for complications after RA.

\section{BMI}

Obesity is an independent risk factor that needs to be considered in surgical decisions regarding adrenalectomy and in all cases of minimally invasive surgery. The relevant literature remains controversial, because there are few reports that specifically analyze the use of robotic techniques in obese patients. Brunaud et al. observed that the robotic approach offered advantages in obese patients with a BMI between 30 to 44 (9). In contrast, Aksoy et al. reported no significant difference in perioperative outcomes between the robot-assisted approach and the laparoscopy approach in obese patients undergoing adrenalectomy (20) and suggested that the hardships in keeping exposure and dissection in high BMI cases reduced the benefits of RA versus LA.

In a study of 66 patients ( 26 obese and 40 non-obese) led by Agcaoglu et al., a BMI $\geq 30 \mathrm{~kg} / \mathrm{m}^{2}$ did not appear to be a risk factor for intra- and post-operative complications (21). A recent paper carried out by Greilsamer et al. (10) analyzed 303 consecutive patients undergoing unilateral transabdominal RA. BMI was not a significant risk factor for conversion, capsular rupture, or postoperative complication. Thus, while it seems that good results on obese patients might be a unique benefit of RA, we should note that a recent series on conventional laparoscopic surgery recorded similar success (22); it is therefore likely that both the laparoscopic and robotic approach can manage obese patients well.

\section{Age}

Data collected from the included studies suggested that age does not seem to be an independent risk factor for the possibility of conversion (23) or for an increase in the incidence of complications (2).

\section{Tumor size}

It is widely accepted that the size of the nodule is a predictor of the difficulty of surgery. In Greilsamer et al.'s series (10), tumor size $>5 \mathrm{~cm}$ was a predictive factor for conversion to an open procedure, which seems to be a common finding for the LA. A study conducted by Calcatera et al. on 200 cases of minimally invasive adrenalectomy (RA and LA) also concluded size of tumor $>5 \mathrm{~cm}$ was a predictive factor for conversion (23). Data related to risk factors for complication in RA were also described in a singlecenter single-surgeon retrospective study carried out by Quadri et al., who pooled 43 patients that underwent RA: there were no significant differences in operative time, length of hospital stay, blood loss, readmission due to any complications, and conversions to open surgery; for tumor size, there was a higher occurrence of complications in patients with tumors $\geq 8$ versus $<8 \mathrm{~cm}$ (17). Data regarding risk factors for complications were also supported by a recent paper carried out by Thompson et al., who analyzed 659 patients undergoing adrenal surgery, 250 of whom underwent robotic surgery. In multivariable analysis, tumor size was associated with a higher risk of conversion to open surgery (2). The reason for the need for conversion is not well described. However, we can deduce that, since there was no reported increase in bleeding, this data, correlated with the over-described BMI, is attributable to an increase in technical difficulty in proceeding with robotic surgery and, more widely, with a minimally invasive technique.

\section{Tumor side}

In Quadri et al.'s paper, there were no significant differences in complications related to side (left versus right) (17). Furthermore, in Greilsamer et al.'s series (10) and in Calcatera's paper (23), the side did not seem to influence the incidence of postoperative complications or the need for conversion. Likewise, no statistically relevant correlations were documented in the Thompson series (2).

\section{Pathology}

Some authors have identified malignancy as a risk factor for complications. For example in Thompson series, the presence of a malignant lesion was linked 
to an increased conversion rate and an increase in postoperative hospitalization, but the pheochromocytoma did not appear to be connected with these events. Greilsamer et al. (10) also examined hypercortisolism and pheochromocytoma, but found that they did not seem to correlate with a worse intra or postoperative outcome. The lack of tactile feedback could be a problem during dissection of pheochromocytoma; in fact, improper gland handling can result in catecholamine liberation (24). Aliyev et al. compared robotic with laparoscopic surgery in the management of pheochromocytoma (25). RA for pheochromocytoma seemed to be equivalent to the laparoscopic technique regarding safety and efficacy; there were also no differences between the 2 approaches regarding the intraoperative hemodynamic parameters.

\section{Previous surgery}

Previous open abdominal surgery is a known factor in the increasing difficulty of a subsequent minimally invasive surgical approach. This condition is in fact often a determining factor in the decision for choosing a laparoscopic versus robotic approach. In the papers we analyzed, it is therefore not widely considered a risk factor for complications. In the Greilsamer series (10), history of previous ipsilateral upper mesocolic or retroperitoneal surgical procedure was found to be an independent predictor for capsular tear but did not correlate with the increased incidence of post-operative complications.

\section{Surgeon experience}

The experience of the surgeon and the importance of a learning curve is accepted as relevant factor in nearly all surgery types. The Greilsamer series (10) clearly showed a statistically significant difference in patients undergoing surgery after completion of the learning curve in regards to the intraoperative complication of capsule rupture. Operative time is also widely considered to be a surrogate indicator of the learning curve (13). Brunaud et al. (9) examined a series of $50 \mathrm{RA}$ procedures and observed a reduction in operative time of 116 minutes reported in the first 20 patients to 87 minutes in the most recent ones.

\section{Conclusions}

The advantage of RA versus the standard minimally invasive approach is still a subject of discussion. RA appears to be safe and should be opted over open adrenalectomy and the LA because of its associated reduction in hospital stay, lower blood loss, and equivalent complication rates. This literature review confirmed that tumor size, malignancy type, the completion of learning curve, and less clearly, previous ipsilateral upper mesocolic or retroperitoneal surgery, were risk factors for postoperative complications and for failure of the robotic approach. In order to be able to best stratify the patients eligible for robotic surgery, further high-quality trials are warranted, especially those analyzing specific risk factors for complications in robotic surgery.

\section{Acknowledgments}

Funding: None.

\section{Footnote}

Provenance and Peer Review: This article was commissioned by the Guest Editor (Özer Makay) for the series "Robotic Adrenalectomy" published in Gland Surgery. The article was sent for external peer review organized by the Guest Editor and the editorial office.

Conflicts of Interest: All authors have completed the ICMJE uniform disclosure form (available at http:// dx.doi.org/10.21037/gs.2020.04.10). The series "Robotic Adrenalectomy" was commissioned by the editorial office without any funding or sponsorship. The authors have no other conflicts of interest to declare.

Ethical Statement: The authors are accountable for all aspects of the work in ensuring that questions related to the accuracy or integrity of any part of the work are appropriately investigated and resolved.

Open Access Statement: This is an Open Access article distributed in accordance with the Creative Commons Attribution-NonCommercial-NoDerivs 4.0 International License (CC BY-NC-ND 4.0), which permits the noncommercial replication and distribution of the article with the strict proviso that no changes or edits are made and the original work is properly cited (including links to both the formal publication through the relevant DOI and the license). See: https://creativecommons.org/licenses/by-nc-nd/4.0/.

\section{References}

1. Barreca M, Presenti L, Renzi C, et al. Expectations and outcomes when moving from open to laparoscopic 
adrenalectomy: multivariate analysis. World J Surg 2003;27:223-8.

2. Thompson LH, Nordenström E, Almquist M, et al. Risk factors for complications after adrenalectomy: results from a comprehensive national database. Langenbecks Arch Surg 2017;402:315-22.

3. Makay O, Erol V, Ozdemir M. Robotic adrenalectomy. Gland Surg 2019;8:S10-6.

4. Teo XL, Lim SK. Robotic assisted adrenalectomy: Is it ready for prime time? Investig Clin Urol 2016;57:S130-46.

5. Morris LF, Perrier ND. Advances in robotic adrenalectomy. Curr Opin Oncol 2012;24:1-6.

6. Nehs MA, Ruan DT. Minimally invasive adrenal surgery: an update. Curr Opin Endocrinol Diabetes Obes 2011;18:193-7.

7. Economopoulos KP, Mylonas KS, Stamou AA, et al. Laparoscopic versus robotic adrenalectomy: A comprehensive meta-analysis. Int J Surg 2017;38:95-104.

8. Brunaud L, Ayav A, Zarnegar R, et al. Prospective evaluation of 100 robotic-assisted unilateral adrenalectomies. Surgery 2008;144:995-1001; discussion 1001.

9. Brunaud L, Bresler L, Ayav A, et al. Robotic-assisted adrenalectomy: what advantages compared to lateral transperitoneal laparoscopic adrenalectomy? Am J Surg 2008;195:433-8.

10. Greilsamer T, Nomine-Criqui C, Thy M, et al. Roboticassisted unilateral adrenalectomy: risk factors for perioperative complications in 303 consecutive patients. Surg Endosc 2019;33:802-10.

11. Lee GS, Arghami A, Dy BM, et al. Robotic single-site adrenalectomy. Surg Endosc 2016;30:3351-6.

12. Samreen S, Fluck M, Hunsinger M, et al. Laparoscopic versus robotic adrenalectomy: a review of the national inpatient sample. J Robot Surg 2019;13:69-75.

13. Brandao LF, Autorino R, Laydner H, et al. Robotic Versus Laparoscopic Adrenalectomy: A Systematic Review and Meta-analysis. Eur Urol 2014;65:1154-61.

14. Nordenström E, Westerdahl J, Hallgrimsson P, et al. A

Cite this article as: Inversini D, Manfredini L, Galli F, Zhang D, Dionigi G, Rausei S. Risk factors for complications after robotic adrenalectomy: a review. Gland Surg 2020;9(3):826-830. doi: 10.21037 /gs.2020.04.10 prospective study of 100 robotically assisted laparoscopic adrenalectomies. J Robot Surg 2011;5:127-31.

15. Winter JM, Talamini MA, Stanfield CL, et al. Thirty robotic adrenalectomies: a single institution's experience. Surg Endosc 2006;20:119-24.

16. Rao N, Ramachandran R, Tandon N, et al. Surgical and Hemodynamic Outcomes in Pheochromocytoma Surgery: A Prospective Cohort Study. Urology 2016;98:103-6.

17. Quadri P, Esposito S, Coleoglou A, et al. Robotic Adrenalectomy: Are We Expanding the Indications of Minimally Invasive Surgery? J Laparoendosc Adv Surg Tech A 2019;29:19-23.

18. Heger P, Probst P, Hüttner FJ, et al. Evaluation of open and minimally invasive adrenalectomy: a systematic review and network meta-analysis. World J Surg 2017;41:2746-57.

19. Agrusa A, Romano G, Navarra G, et al. Innovation in endocrine surgery: robotic versus laparoscopic adrenalectomy. Meta-analysis and systematic literature review. Oncotarget 2017;8:102392-400.

20. Aksoy E, Taskin HE, Aliyev S, et al. Robotic versus laparoscopic adrenalectomy in obese patients. Surg Endosc 2013;27:1233-6.

21. Agcaoglu O, Akbas M, Ozdemir M, et al. The Impact of Body Mass Index on Perioperative Outcomes of Robotic Adrenalectomy: An Update. Surg Innov 2019;26:687-91.

22. Coste T, Caiazzo R, Torres F, et al. Laparoscopic adrenalectomy by transabdominal lateral approach: 20 years of experience. Surg Endosc 2017;31:2743-51.

23. Calcatera NA, Hsiung-Wang C, Suss NR, et al. Minimally Invasive Adrenalectomy for Adrenocortical Carcinoma: Five-Year Trends and Predictors of Conversion. World J Surg 2018;42:473-81.

24. Brandao LF, Autorino R, Zargar H, et al. Robot-assisted laparoscopic adrenalectomy: step-by-step technique and comparative outcomes. Eur Urol 2014;66:898-905.

25. Aliyev S, Karabulut K, Agcaoglu O, et al. Robotic versus laparoscopic adrenalectomy for pheochromocytoma. Ann Surg Oncol 2013;20:4190-4. 